This item was submitted to Loughborough's Research Repository by the author.

Items in Figshare are protected by copyright, with all rights reserved, unless otherwise indicated.

\title{
Modelling the wind energy resources in complex terrain and atmospheres. Numerical simulation and wind tunnel investigation of non-neutral forest canopy flows
}

\section{PLEASE CITE THE PUBLISHED VERSION}

http://dx.doi.org/10.1016/j.jweia.2017.03.014

\section{PUBLISHER}

Elsevier @ Crown Copyright

VERSION

AM (Accepted Manuscript)

\section{PUBLISHER STATEMENT}

This work is made available according to the conditions of the Creative Commons Attribution-NonCommercialNoDerivatives 4.0 International (CC BY-NC-ND 4.0) licence. Full details of this licence are available at: https://creativecommons.org/licenses/by-nc-nd/4.0/

\section{LICENCE}

CC BY-NC-ND 4.0

\section{REPOSITORY RECORD}

Desmond, Cian, Simon J. Watson, and Philip Hancock. 2019. "Modelling the Wind Energy Resources in Complex Terrain and Atmospheres. Numerical Simulation and Wind Tunnel Investigation of Non-neutral Forest Canopy Flows". figshare. https://hdl.handle.net/2134/24843. 


\title{
Modelling the wind energy resources in complex terrain and atmospheres. Numerical simulation and wind tunnel investigation of non-neutral forest canopy flows
}

\author{
Cian J. Desmond ${ }^{a}$, Simon J. Watson ${ }^{b}$, Philip E. Hancock ${ }^{c}$
}

\author{
a Marine and Renewable Energy Ireland (MaREI), University College Cork \\ (UCC), Ireland \\ ${ }^{b}$ Centre for Renewable Energy Systems Technology (CREST), Loughborough \\ University, UK
}

'EnFlo Laboratory, Faculty of Engineering and Physical Sciences, University of Surrey, Guildford, UK

\begin{abstract}
A series of experiments have been conducted in a stratifiable Atmospheric Boundary Layer (ABL) wind tunnel, using neutral and stable conditions, in which a forest canopy has been represented by use of architectural model trees. These experiments have been replicated in Computation Fluid Dynamic (CFD) simulations using a previously validated methodology.

Both the numerical simulations and the experimental data show that atmospheric stability has a significant effect on the development and extent of the forest wake and on the prevalence of the canopy flow features such as the sub-canopy jet. The analysis shows that it is possible to include both forestry and buoyancy effects in numerical simulations using two sets of source and sink terms and achieve satisfactory convergence. However, it is shown that the numerical simulations overestimate the effects of thermal stratification when using the standard configuration.
\end{abstract}

\section{Introduction}

Until recently, flow modelling for commercial wind resource assessments has largely been conducted using linearised flow modelling software [Sanz Rodrigo, 2010] such as WAsP [Troen \& De Bass, 1987]. These software packages, which were developed in the 1970's and 1980's, have allowed resource assessments to be conducted rapidly by users with minimal training using the resources available on a standard personal computer. As we move to more complex wind farm sites and as the 
acceptable level of modelling uncertainty reduces, these simplified solvers are being asked to perform calculations outside of their operational capabilities.

Fortunately, the computational power required to run full CFD simulations on the scale of a typical wind farm are becoming increasingly affordable and as a result CFD is beginning to see greater adoption by industry [Mortensen \& Jørgensen, 2013]. Following this trend, research activities have increased into the flow dynamics generated by non-trivial terrain and atmospheric features in order to fully realise the capabilities of CFD to describe the ABL and to meet the standards demanded in this era of financial rigor.

One element of terrain complexity, which has been identified as requiring special attention in CFD simulations, is the presence of forestry [TPWind, 2008 and Sanz Rodrigo, 2010]. Trees are living, breathing organisms which exert a considerable drag force on the wind, introduce turbulence and alter local temperature and heat flux profiles. The aggregated effect of these factors is an extremely complicated flow regime in the vicinity of forest canopies which presents a significant challenge to the micrometeorologist.

The extent of this challenge was clearly demonstrated in Brower et al. (2014) where it was shown that the presence of forestry increases modelling uncertainty by a factor of 4-5 regardless of the computational flow modelling technology used. One reason for these elevated levels of uncertainty when modelling forest canopy flows may be the occurrence of non-neutral atmospheric stability. It is generally assumed that, at the wind speeds at which wind turbines operate, inertial forces will prevail over those induced by buoyancy forces and so it is unnecessary to include these effects in commercial resource assessments. However, in Desmond and Watson (2014) analysis of data from four heavily forested European sites showed that stability effects were prevalent for wind speeds of up to $10 \mathrm{~m} / \mathrm{s}$.

It has been suggested by various authors that buoyancy effects can have a significant impact on how the wind interacts with forest canopies (Brunet \& Irvine, 2000 and Morse et al., 2002). Thus the assumption of neutral stability when modelling wind flow in forested sites may contribute significantly to the uncertainty associated with such calculations.

In this paper we examine the use of CFD to model the combined effects of atmospheric stability and canopy drag on the wind resource. This type of CFD modelling is complicated by the fact that two sets of source and sink terms must be included in the Reynolds Averaged Navier Stokes (RANS) equations. It is therefore desirable to use a dataset with a high density of measurement points in order to validate the CFD model. In this paper we use ABL wind tunnel data in which the forest canopy was represented by architectural model trees. Such data were successfully used to validate CFD models in Desmond et al. (2014) where experiments were conducted at the Lucien Malavard wind tunnel which is located in the Laboratoire Prisme, Orléans University, France. For this paper, similar experiments were conducted at the stratifiable EnFlo tunnel located at the University of Surrey, UK.

The work presented in this paper is an example of hybrid modelling in that it uses both experimental and physical approaches to investigate the problem. Further examples of this hybrid modelling approach are discussed in Meroney (2016).

\section{Experimental data}

The miniature forest used in Desmond et al. (2014) was recreated for this series of experiments. This forest configuration is comprised of a range of 100 architectural model trees, see example in 
Figure 1 , selected to ensure that the vertical structure and height of the canopy was strongly heterogeneous in order to allow realistic three dimensional flow patterns to develop. Specifics on the forest configuration and the photographic analysis method used to determine the canopy structure can be found in Desmond et al. (2014).

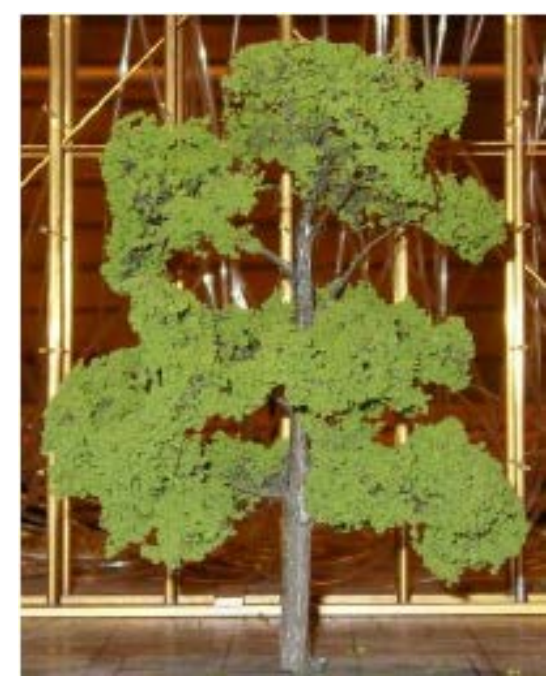

Figure 1. An example of the type of architectural model tree used for experimentation.

Whilst there is a long history of wind tunnel experiments considering flow over non-trivial terrain and through vegetation (Meroney and Neff, 1993), wind tunnels are generally only able to consider neutrally stratified flows. However, there are a limited number of $A B L$ wind tunnels which can be thermally stratified. The EnFlo atmospheric boundary layer tunnel located at the University of Surrey, UK is such a facility and is shown schematically in Figure 2.

This is a twin-fan suck-through facility with an operational section of $1.5 \mathrm{~m}$ high $\times 3.5 \mathrm{~m}$ wide $\times 20 \mathrm{~m}$ long and an operating range of $0.3-4.5 \mathrm{~m} / \mathrm{s}$. Stratification is achieved via fully adjustable heating elements $(405 \mathrm{~kW})$ at the inlet along with heating $\left(5 \mathrm{~kW} / \mathrm{m}^{2}\right)$ and cooling $\left(1 \mathrm{~kW} / \mathrm{m}^{2}\right)$ panels on the floors and walls. A maximum stratification of $80^{\circ} \mathrm{C} / \mathrm{m}$ can be achieved in the tunnel which is necessary in order to achieve the required scaled thermal stratifications. 


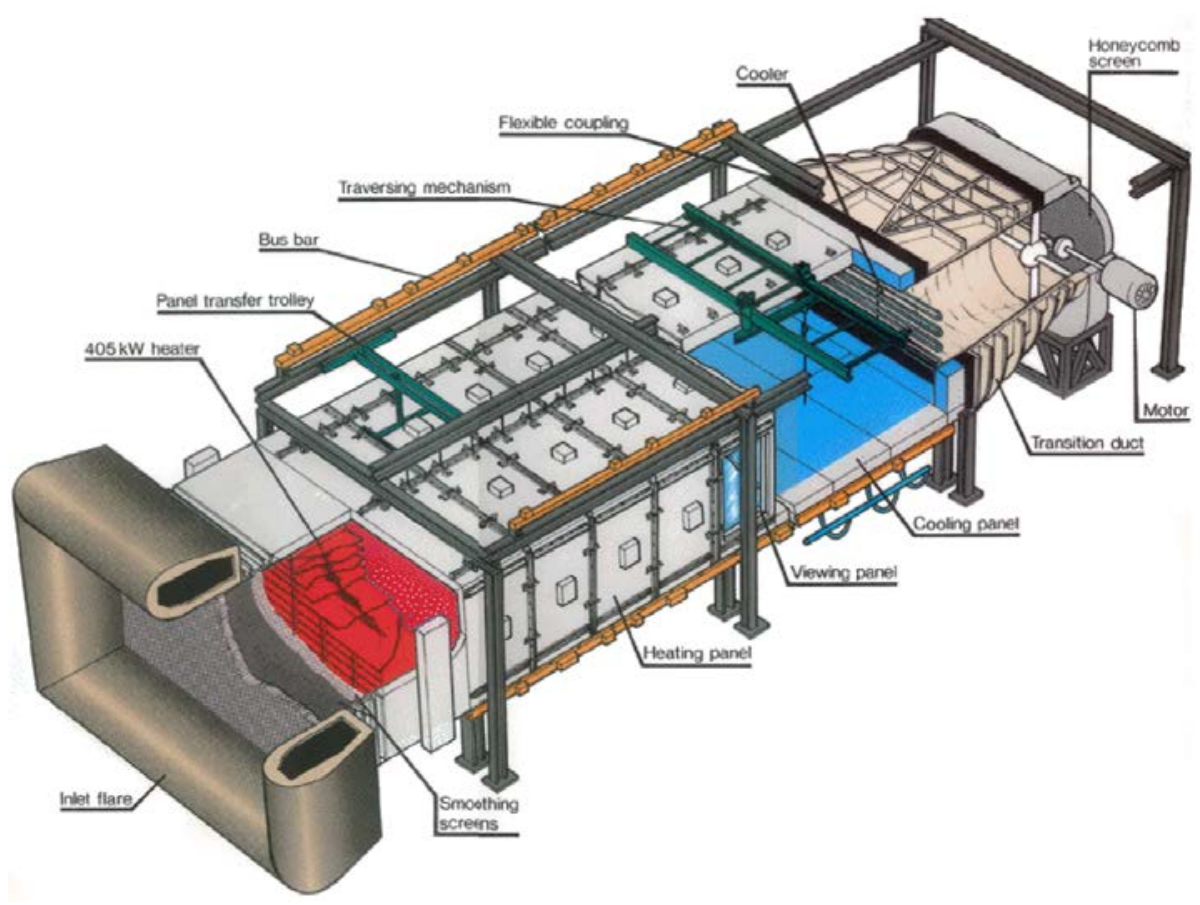

Figure 2. The stratifiable EnFlo wind tunnel at the University of Surrey. [Picture credit: www.surrey.ac.uk]

An $A B L$ is simulated in the tunnel by use of a fabric honeycomb smoothing screen, Irwin spires and a series of metallic angles arranged on the tunnel floor. These metallic angles provide surface roughness and were placed throughout the tunnel up to the start of the forest. In the lee of the forest no roughness elements were present. Velocity measurements are made at this facility by use of Dantec Fibre-Flow two-component Laser Doppler Anemometry (LDA). A laser unit is moved into position by use of a fully adjustable traverse system. From this unit, two pairs of lasers are projected and meet at a distance of approximately $300 \mathrm{~mm}$ from the head of the unit. One pair of lasers, coloured blue, are arranged on the z-axis whilst the second, coloured green, are arranged on the $\mathrm{x}$ axis. Transmitting optics in the laser unit head relays images of the interference pattern produced by particles moving through the focal point of the lasers for a period of just approximately 3 minutes.

The main source of error associated with this system is in the statistical sampling, this error can be reduced by collecting data for a sufficiently long period such that a statistical characteristics of the sample are representative of the true conditions in the measurement volume. The sampling interval, used in this study were based on previous related studies and repeat-of-measurement checks. These intervals have been determined to be sufficient to provide a $99 \%$ confidence interval for the measurements of mean velocity within a band of $\pm 1 \%$, and the Reynolds stresses within $\pm 10 \%$ of the respective maximum.

Analysis of these data allows both mean and mean correlations to be calculated for the stream wise, $\mathrm{U}$, and vertical, $\mathrm{W}$, wind components observed in the control volume generated at the focal point of the lasers, which is approximately $3 \mathrm{~mm}^{3}$. Data can also be determined for the lateral, $\mathrm{V}$, wind component by orientating the laser unit appropriately.

Measurements are taken by the LDA at a rate of 50 to $200 \mathrm{~Hz}$ depending on the number of particles available in the flow. In order to increase this to the upper range, the air drawn into the tunnel is 
seeded with a fine mist of water containing dissolved sugar which is produced in an ultrasonic vaporiser.

Temperature measurements are taken by use of a fine cold wire thermometer which is located 3 to $4 \mathrm{~mm}$ downstream of the control volume under investigation, corrected for the spatial displacement. The cold wire thermometer is calibrated to $\pm 0.1 \mathrm{~K}$. A measurement interval of approximately 3 minutes is again used to provide a $99 \%$ confidence interval within $\pm 10 \%$ of the recorded value based on previous related studies.

For this research, initial experiments were conducted at the EnFlo facility in which the tunnel was operated in neutral configuration in order to provide reference data. Additional experiments were then conducted in which a surface and free stream stratification were introduced to develop a stable boundary layer. Whilst it is now possible to conduct unstable experiments in the EnFlo facility (Hancock et al., 2013), this option was not available at the time of experimentation.

Wind speed measurements around the forest canopy were performed for a total of 333 points using the LDA and cold wire thermometer. Of these, 253 were taken in a series of profiles of 23 measurements between $20 \mathrm{~mm}$ and $600 \mathrm{~mm}$ above the surface of the tunnel and separated vertically with a logarithmic distribution to concentrate measurements in the lowest $150 \mathrm{~mm}$. One of these profiles was taken $200 \mathrm{~mm}$ upstream of the forest in order to characterise the boundary layer. The other ten profiles were positioned at $h_{c}, 2 h_{c}, 3 h_{c}, 4 h_{c}, 5 h_{c}, 10 h_{c}, 15 h_{c}, 20 h_{c}, 30 h_{c}$ and $40 h_{c}$ downstream of the forest along the centreline. In this case, $h_{c}$ is taken to be $80 \mathrm{~mm}$ which is approximately equal to the average canopy height.

The remaining measurements were taken along two lines as shown in Figure 3.

The first line was located at a height of $120 \mathrm{~mm}$ above the wind tunnel floor across the top of the forest along the centreline parallel to the $x$-axis. A total of 40 measurements were taken at equal intervals covering the entire length of the forest. 
The second line of measurements was positioned $2 h_{c}$ behind the forest at a height of $100 \mathrm{~mm}$ and contained a total of 40 measurements running parallel to the forest edge and the $y$-axis. This line of measurements again covered the entire length of the forest.
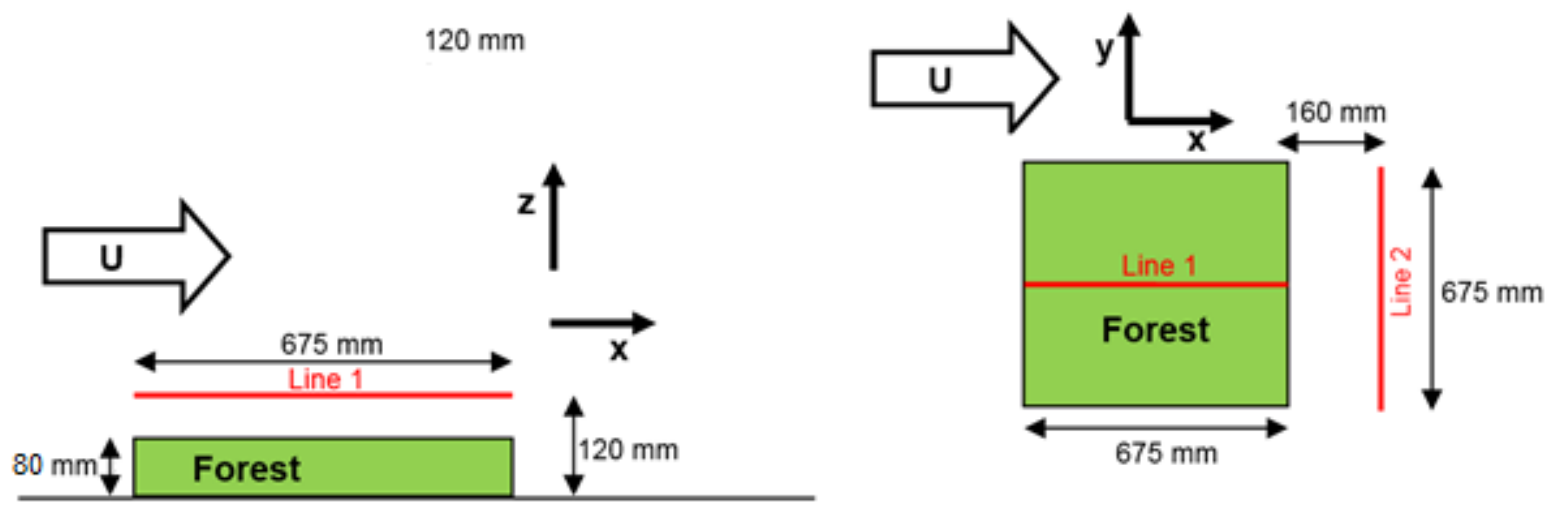

Figure 3. Schematic view showing the position of the additional measurement lines. The U-arrow indicates the stream wise wind direction.

Information on the specifics of the neutral and stable experimental configurations is given in the following sections.

\subsection{Neutral wind tunnel configuration}

Metal angled-strips were placed in an ordered pattern on the tunnel floor in order to replicate the roughness that would be expected in a rural area at a scale of 1:300. The resulting boundary layer had a free stream velocity $\mathrm{U}_{\infty}=2.5 \mathrm{~m} / \mathrm{s}$ with aerodynamic roughness length $\mathrm{Z}_{\mathrm{o}}=0.001 \mathrm{~m}$ and friction velocity $U_{*}=0.14 \mathrm{~m} / \mathrm{s}$. These values of $\mathrm{Z}_{\mathrm{o}}$ and $\mathrm{U}_{*}$ were estimated by fitting a logarithmic profile to the experimental velocity data.

As discussed, the LDA system is capable of taking measurements for two of the three velocity components. In this case, measurements were made for the mean streamwise, $\mathrm{U}(\mathrm{z})$, and vertical, $\mathrm{W}(\mathrm{z})$, velocity components. In order to provide data analogous to the CFD outputs it is necessary to estimate the magnitude of the mean lateral, $\mathrm{V}(\mathrm{z})$, component of the velocity. This was achieved by analysis of the Orléans data set (Desmond et al., 2014) where measurements were taken using stereo-PIV (Schröder and Willert, 2008) and thus data for the three velocity components were available. It is difficult to quantify the experimental error associated with the stereo-PIV measurement technique. A discussion on potential error sources and a suggested uncertainty analysis methodology can be found in Zhang et al. (2002). By probabilistic theories, you can assess the statistical uncertainty of the ensemble-averaged values, according to the number of samples (image pairs) and the standard-deviation of this ensemble-average with a confidence interval. In the case of the Orléans data set, 1000 image pairs were recorded. These can be considered to be independent as the PIV system is non-time-resolved. The error obtained for the ensemble-average velocity $\mathrm{U}$ for a $95 \%$ confidence interval will be:

$$
\pm \frac{1.96 \sigma_{u}}{\sqrt{N}}
$$


Where, $\sigma_{u} \quad$ Is the standard deviation of velocity measurements

Using this method, the $95 \%$ confidence interval for the velocity measurements in the Orléans dataset is $0.059 \mathrm{~m} / \mathrm{s}$. A full discussion on the application of this statistical approach can be found in Thacker et al., 2010.

Through analysis of these data the following relationships were established for mean and turbulent $\left(\mathrm{u}^{\prime}(\mathrm{z}), \mathrm{v}^{\prime}(\mathrm{z}), \mathrm{w}^{\prime}(\mathrm{z})\right)$ components of the velocity:

$$
\begin{gathered}
\mathrm{V}(\mathrm{z}) \approx \mathrm{W}(\mathrm{z}) \\
\mathrm{v}^{\prime}(\mathrm{z}) \approx 0.3675 \times\left[\mathrm{u}^{\prime}(\mathrm{z})+\mathrm{w}^{\prime}(\mathrm{z})\right]
\end{gathered}
$$

These relationships were used to produce three dimensional velocity and Turbulent Kinetic Energy measurements for each of the 333 measurement points from the EnFlo experiments.

\subsection{Stable wind tunnel configuration}

For this experiment, the same roughness elements were used in the same configuration as for the neutral experiment described in Section 2.1. The free stream velocity was reduced to $U_{\infty}=1.5 \mathrm{~m} / \mathrm{s}$ and a thermal stratification was introduced as shown in Figure 4

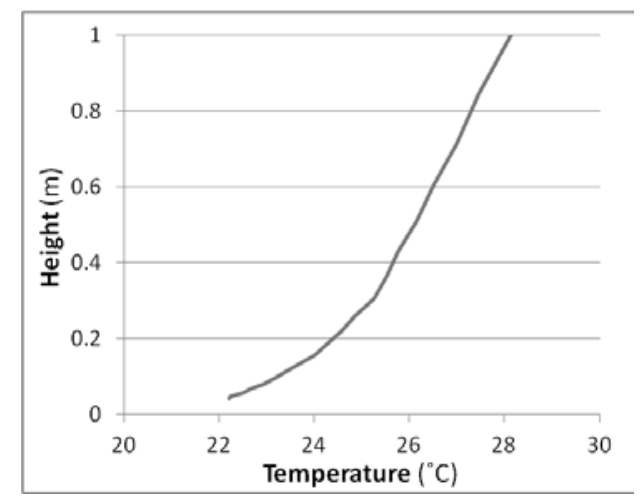

Figure 4. Temperature profile used in the EnFlo wind tunnel for the stable experiments.

It was again necessary to estimate the magnitude of the lateral - $V$ velocity component. Although the relative magnitudes of the three velocity components may be different when the effects of stability are involved, in the absence of a more satisfactory solution, the relationships described by Eq. 1 and 2 were used. The stability of the ABL generated in the tunnel can be quantified using the Richardson Number, Ri (Kaimal \& Finnigan, 1994). This is a non-dimensional parameter which relates the importance of buoyancy and shear forces in creating turbulence within the $A B L$. It requires measurements of both temperature and wind speed at two heights and is defined by:

$$
\mathrm{Ri}=\frac{\mathrm{g}}{\overline{\bar{\theta}}}\left[\frac{\partial \bar{\theta} / \partial \mathrm{z}}{(\partial \overline{\mathrm{U}} / \partial \mathrm{z})^{2}}\right]
$$

Where, g Acceleration due to gravity 
Applying this metric to the wind tunnel between a height of $0.1 \mathrm{~m}$ and $0.5 \mathrm{~m}$ a value of $\mathrm{Ri}=0.106$ is calculated. According to Mannan and Lee, 2005 , a value of $\mathrm{Ri}>0.03$ indicates stable stratification of an ABL. However, caution should be taking in the interpretation of the magnitude of this parameter as the values do not necessarily scale.

\section{CFD simulations}

The commercially available CFD software ANSYS CFX 14.0 was used for this study. CFX contains a coupled solver for mass and momentum which allows the Reynolds Averaged Navier Stokes (RANS) forms of the governing equations to be solved for a user defined node-centred grid using an algebraic multi-grid algorithm for convergence acceleration.

The CFD model domain used for this analysis was $5.7 \mathrm{~m}$ long $\times 2.3 \mathrm{~m}$ wide $\times 1 \mathrm{~m}$ high and was meshed using an unstructured tetrahedral mesh which was refined in two zones. The first, Zone 1 , coincided with the volume of the porous sub domain representing the forest. The second, Zone 2, extended to $40 \mathrm{~h}_{\mathrm{c}}$ behind, $7 \mathrm{~h}_{\mathrm{c}}$ in front, $4 \mathrm{~h}_{\mathrm{c}}$ above and $3 \mathrm{~h}_{\mathrm{c}}$ to either side of the forest. A constant cell size of $7.5 \mathrm{~mm}$ was used in Zone 1 whilst a constant cell size of $10 \mathrm{~mm}$ was used in Zone 2 . The distance from the inlet to the edge of the forest was set to $1 \mathrm{~m}$ with $4 \mathrm{~m}$ from the forest edge to the outlet.

A five cell inflation layer of hexahedral elements was defined at the lower boundary of the domain which represented the floor of the tunnel. The first cell height was set at $2.4 \mathrm{~mm}$ with an expansion factor of 1.2. This configuration resulted in a total of $16,774,974$ elements.

Simulations were conducted on the Loughborough University research High Performance Computing (HPC) cluster which consists of 161 nodes, each having two six-core Intel Westmere Xeon X5650 CPUs and 24GB of memory. Each simulation was divided among twelve cores.

The CFD domain, mesh configuration and computational resources used for these simulations were identical that those used in Desmond et al. (2014). For additional details, specifically relating to the mesh sensitivity study, the reader is directed to that paper. The main findings of that study are summarise in Figure 5 where velocity and turbulent kinetic energy profiles are have been extracted for a profile centred on the forest and located at a distance of $2 h_{c}$ in the lee of the obstruction for the three meshes considered, Coarse, Medium and Fine. The number of elements in the CFD domain doubled for each increase in mesh refinement. 


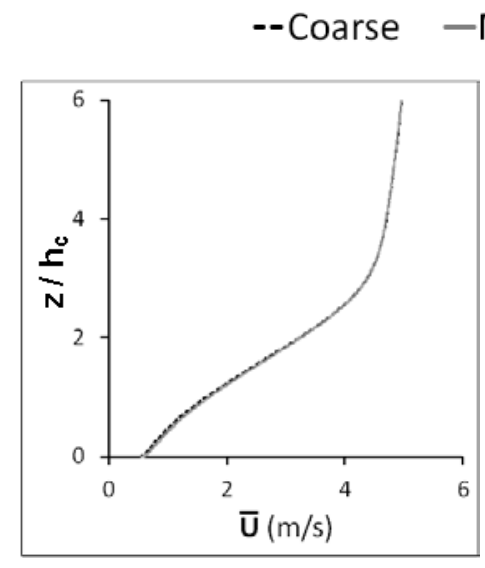

(a) Velocity

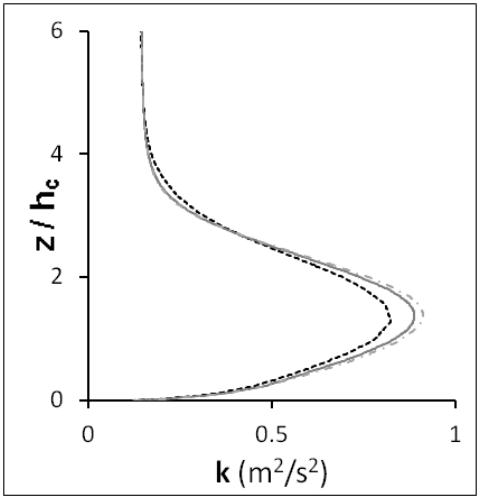

(b) Turbulent kinetic energy

Figure 5. Results of the mesh sensitivity study presented in Desmond et al. (2014).

As can be seen in Figure $5(\mathrm{a})$, a minimal alteration to the simulated mean velocity values is obtained by refining the mesh. The effect of a finer resolution is observed to a greater degree in the Turbulent Kinetic Energy profiles presented in Figure 5 (b) where there is a difference in the magnitude of the peak simulated value of $0.06 \mathrm{~m}^{2} / \mathrm{s}^{2}$ between results achieved using the Coarse and Medium meshes. This reduces to a difference of just $0.02 \mathrm{~m}^{2} / \mathrm{s}^{2}$ when we compare values achieved using the Medium and Fine meshes which otherwise shows strong agreement away from these peak values. As these are modest changes to these key parameter, and the fine mesh simulations require 4.4 times the computation time, the medium mesh was used for all simulations in this paper.

The maximum observed skewness for the mesh used was 0.84 with a mean value of 0.2 and a standard deviation of 0.11 . Generally, a skewness of $<0.95$ is taken as being acceptable and $<0.25$ deemed excellent (ANSYS Inc., personal communication, November, 2010).

Given the results of the analysis presented in Desmond et al. (2014), the Shear Stress Transport turbulence closure (Menter, 1994) was used for all simulations, the geometry of the forest was represented as a single porous block and the leaf area density was averaged in $\mathrm{x}, \mathrm{y}$ but allowed to vary in z. This corresponds with morphology Level B2 as described in Desmond et al. (2014).

The numerical approximations used in the advection scheme for continuity, momentum and heat transfer are as per the high resolutions scheme described in [ANSYS, 2017]. For turbulence, the $1^{\text {st }}$ order upwind differencing scheme is used whilst for pressure a Linear-Linear interpolation scheme is used. For the transient term, the $2^{\text {nd }}$ order backward Euler method is used. Details on these methods can be found in [ANSYS,2017]

The convergence criteria used was $10^{\wedge}-4$ for all terms with the exception of turbulent kinetic energy for which $10^{\wedge}-3$ was used. All simulations conducted during the mesh sensitivity study and during simulations for which results are presented satisfied these convergence criteria.

The boundary conditions required for the neutral and stable simulations are described in the following two sections.

\subsection{Neutral CFD configuration}

The velocity profile was described using the $\log$ law with $\mathrm{Z}_{\mathrm{o}}=0.001 \mathrm{~m}$ and $\mathrm{U}_{*}=0.1355 \mathrm{~m} / \mathrm{s}$.

The aerodynamic roughness length, $\mathrm{z}_{\mathrm{o}}$, can be converted to the equivalent sand grain roughness length, $\varepsilon_{\mathrm{S}}$, using Eq. 4. (McCormick et al., 2012). The aerodynamic roughness was used for the 
calculation of the wind profile but was not applied to the floor of the CFD domain. This is analogous to the conditions in the wind tunnel where surface roughness elements were not present on the floor of the tunnel.

$$
\varepsilon_{\mathrm{s}}=\mathrm{z}_{0} * \exp (8.48 \kappa)
$$

Where,

The Turbulent Kinetic Energy and its dissipation rate were described using the standard Richards and Hoxey equations (Richards and Hoxey, 1993), these values were used to set the domain boundary conditions for the SST simulations, it was not necessary to prescribe a value of the Turbulent Eddy Frequency, $\omega$. It was found that a value of $\mathrm{C}_{\mu}=0.07$ gave a better fit to observed turbulence measurements in the tunnel particularly for heights of less than $0.2 \mathrm{~m}$. These conditions were applied at the boundaries. The profiles in Figure 6 have been extracted from the CFD at distance of $200 \mathrm{~mm}$ upstream of the forest in order to coincide with the boundary layer characterisation measurements from the wind tunnel.

$$
\text { - WIND TUNNEL — CFD - - -INLET }
$$

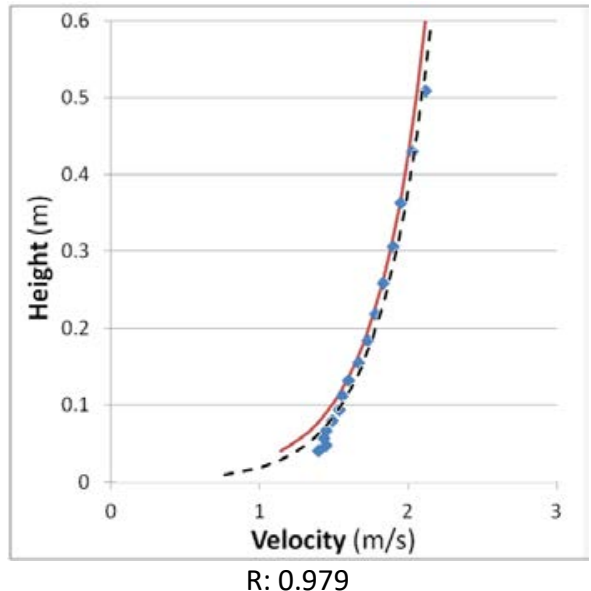

(a)

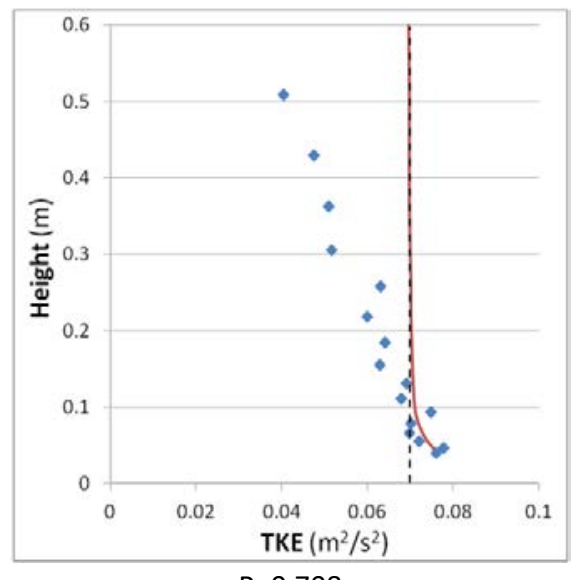

R: 0.708

(b)

Figure 6. Velocity (a) and Turbulent Kinetic Energy (b) profiles in the CFD compared to the Wind Tunnel for the neutral simulation. The average canopy height in this experiment is $h_{\mathrm{cv}}=80 \mathrm{~mm}$

The CFD velocity profile provides a reasonable fit to the observations in the wind tunnel with some divergence above $0.5 \mathrm{~m}$. The Turbulent Kinetic Energy profile in the CFD is significantly different to the observed values particularly above $0.3 \mathrm{~m}$. Various attempts were made to eliminate this by using alternative TKE inlet profiles, however, this resulted in undesirable problems with horizontal heterogeneity within the domain. Although not ideal, the presented formulation was found to provide the most acceptable solution in terms of matching observations and limiting development of the boundary layer within the CFD domain.

\subsection{Stable CFD configuration}

For heights of less than $0.3 \mathrm{~m}$ the experimental velocity profile can be described by a stability dependent version of the log law as shown in Eq. 6 . This equation is adapted from the equation 
suggested by Kaimal and Finnigan (1994) where a coefficient of 5 was used for the $\frac{\mathrm{z}}{\mathrm{L}}$ term. A coefficient of 4 was found to provide a better fit to the wind data observed in the EnFlo experiments.

$$
\mathrm{U}(\mathrm{z})=\frac{\mathrm{U}_{*}}{\mathrm{k}} \cdot\left[\ln \left(\frac{\mathrm{z}}{\mathrm{z}_{0}}\right)+4\left(\frac{\mathrm{z}}{\mathrm{L}}\right)\right]
$$

Where, $\mathrm{Z}_{0}=0.001 \mathrm{~m}$ as per the neutral experiment and $\mathrm{L}=1.94 \mathrm{~m}$.

For heights of above $0.3 \mathrm{~m}$ the velocity profile is described by the power law, Eq. 6, with Uref $=1.4$ $\mathrm{m} / \mathrm{s}$ at $\mathrm{Zref}=0.5 \mathrm{~m}$ and $\alpha=1.4$.

$$
\mathrm{U}(\mathrm{z})=\mathrm{U}\left(\mathrm{z}_{\mathrm{ref}}\right) \times\left(\mathrm{z} / \mathrm{z}_{\mathrm{ref}}\right)^{\alpha}
$$

$\begin{array}{llll}\text { Where, } & \mathrm{U}_{\mathrm{ref}} & \text { Velocity at reference height } \mathrm{r}_{\mathrm{ref}} & (\mathrm{m} / \mathrm{s}) \\ & \text { Zref } & \text { Reference height } & (\mathrm{m}) \\ \mathrm{U}(\mathrm{z}) & \text { Mean velocity at height z } & (\mathrm{m} / \mathrm{s}) \\ \mathrm{z} & \text { Height above the surface } & (\mathrm{m}) \\ \alpha & \text { Shear exponent } & (-)\end{array}$

The Turbulent Kinetic Energy profile was described by Zilitinkevich et al. (1998):

$$
\mathrm{k}(\mathrm{z})=\frac{\mathrm{U}_{*}^{2}}{\sqrt{\mathrm{C}_{\mu}}} \cdot\left[1-\frac{\mathrm{z}}{\mathrm{L}}\right]^{1.68}
$$

In this case the standard value of $\mathrm{C}_{\mu}=0.09$ was used (Richards and Hoxey, 1993). The rate of Turbulent Eddy Dissipation was described by [Zilitinkevich et al., 1998]:

$$
\varepsilon(\mathrm{z})=\frac{\mathrm{U}_{*}{ }^{3}}{\kappa+\mathrm{z}} \times 1.03 \times \exp \left[-2.8\left(\frac{\mathrm{z}}{\mathrm{L}}\right)^{2}\right] \times \mathrm{EdCorr}
$$

Where,

$$
\text { EdCorr }=1+\left[\frac{0.015}{\mathrm{z}}\right]^{0.9} \times\left[\ln \frac{\mathrm{z}}{\mathrm{z}_{0}}\right]
$$

The resulting profiles for velocity and Turbulent Kinetic Energy are given in Figure 7 where they are compared to measurements up stream of the forest in the wind tunnel. As can be seen there is excellent agreement for the velocity profile whilst the Turbulent Kinetic Energy profile used in the CFD is less representative of the observed values in the wind tunnel. 


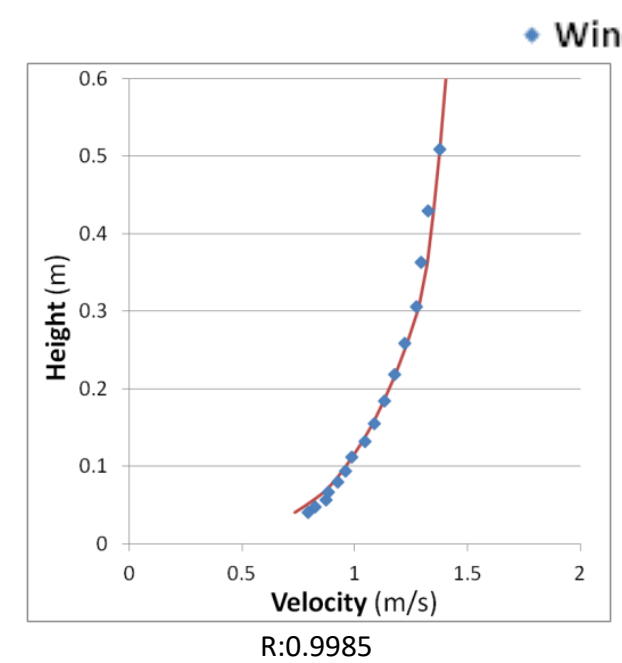

(a)

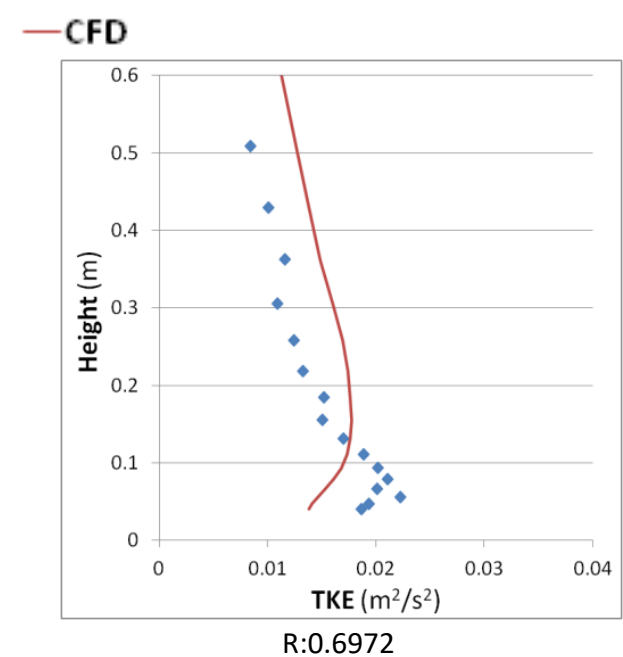

(b)

Figure 7. Velocity (a) and Turbulent Kinetic Energy (b) profiles in the CFD compared to the Wind Tunnel for the stable simulations.

The pressure, $\mathrm{P}$, at the domain outlet was set as:

$$
P(z)=\rho \times \frac{9.81}{\theta(z)} \times \frac{1}{2}[\theta(z)-\theta(0)] \times z
$$

Where, $\theta$ is the potential temperature in degrees Kelvin. This is taken as being equal to the temperature profile as shown in Figure 4 which is also used for temperature boundary conditions in the CFD on all boundaries. A heat flux of $-80 \mathrm{~W} / \mathrm{m}^{2}$ was applied to the floor surface in order to mimic the actual conditions in the wind tunnel. The Coriolis force was neglected for these simulations as the effect will be negligible over the 1.5 metre height of the tunnel.

\subsection{CFD source and sink terms}

The CFD modelling conducted for this paper is complicated by the fact that two sets of source and sink terms must be included in the RANS equations to include the effect of both forestry and stability. A unified modelling approach using a single set of source and sink terms was suggested in [Sogachev et al., 2012], however this has not been numerically verified in ANSYS CFX.

\subsubsection{Forestry source and sink terms}

In order to represent a forest canopy within a CFD model when using the SST turbulence model it is necessary to introduce a porous sub-domain. By including production terms for Turbulent Kinetic Energy, k, Turbulent Eddy Frequency, $\omega$, Turbulent Eddy Dissipation rate, $\varepsilon$, and a drag term in the momentum equations the effect of a forest canopy can be simulated mathematically within this subdomain. This is achieved by the use of the source terms in the governing equations for momentum and turbulent transportation. In the momentum equations, the drag term is:

$$
\mathrm{F}_{\mathrm{i}}=-\rho \mathrm{C}_{\mathrm{d}} \mathrm{A}(\mathrm{z})|\mathrm{U}| \mathrm{U}_{\mathrm{i}}
$$

$\begin{array}{llll}\text { Where, } & \mathrm{F}_{\mathrm{i}} & \text { Drag force per unit volume in the i-direction } & \left(\mathrm{kg} / \mathrm{m}^{2} \cdot \mathrm{s}^{2}\right) \\ \mathrm{A}(\mathrm{z}) & \text { Leaf area density at height } \mathrm{z} & \left(\mathrm{m}^{-1}\right) \\ |\mathrm{U}| & \text { The modulus of the windspeed } & (\mathrm{m} / \mathrm{s})\end{array}$


The corresponding source term for Turbulent Kinetic Energy, k, is given by:

$$
\mathrm{S}_{\mathrm{k}}=\rho \mathrm{C}_{\mathrm{d}} \mathrm{A}(\mathrm{z})|\mathrm{U}|\left[\beta_{\mathrm{p}}|\mathrm{U}|^{2}-\beta_{\mathrm{d}} \mathrm{k}\right]
$$

Where, $\beta_{\mathrm{p}}$ and $\beta_{\mathrm{d}}$ are constants, the values of which are given in Table 1 . The source term for Turbulent Eddy Dissipation rate, $\varepsilon$, is given by:

$$
\mathrm{S}_{\varepsilon}=\rho C_{\mathrm{d}} \mathrm{A}(\mathrm{z})|\mathrm{U}| \varepsilon\left[\frac{\mathrm{C}_{\varepsilon 4} \beta_{\mathrm{p}}|\mathrm{U}|^{2}}{\mathrm{k}}-\mathrm{C}_{\varepsilon 5} \beta_{\mathrm{d}}\right]
$$

Where, $\mathrm{C}_{\varepsilon 4}$ and $\mathrm{C}_{\varepsilon 5}$ are constants, the values of which are also given in Table 1 . The source term for turbulent eddy frequency, $\omega$, is given by:

$$
\mathrm{S}_{\omega}=\rho \mathrm{C}_{\mathrm{d}} \mathrm{A}(\mathrm{z})|\mathrm{U}| \omega\left[\frac{\left(\mathrm{C}_{\varepsilon 4}-1\right) \beta_{\mathrm{p}}|\mathrm{U}|^{2}}{\mathrm{k}}-\left(\mathrm{C}_{\varepsilon 5}-1\right) \beta_{\mathrm{d}}\right]
$$

A discussion on the formulation of these equations can be found in Lopes da Costa (2007) and Sogachev (2009). The appropriate value for the modelling constants in the above equations has been an area of some research (Wylie, 2014). For this research the values as recommended by Lopes da Costa (2007), are used and these are summarised in Table 1.

\begin{tabular}{|c|c|}
\hline Constant & Value \\
\hline$\beta_{\mathrm{p}}$ & 0.17 \\
\hline$\beta_{\mathrm{d}}$ & 3.37 \\
\hline $\mathrm{C}_{\varepsilon 4}$ & 0.9 \\
\hline $\mathrm{C}_{\varepsilon 5}$ & 0.9 \\
\hline
\end{tabular}

Table 1: Modelling constants used for the canopy model.

[Lopes da Costa, 2007]

\subsubsection{Stability source and sink terms}

In CFX, the effects of stability are modelled by the addition of various terms to the RANS equations. A summary of these is given in Montavon (1998) and McCormick et al. (2012). The appropriate term for the momentum equation is given in Eq. 15:

$$
\mathrm{P}_{\mathrm{m}}=\mathrm{g} \beta \rho_{\mathrm{ref}}\left(\mathrm{T}-\mathrm{T}_{\mathrm{ref}}\right) \delta_{\mathrm{i} 3}
$$

$\begin{array}{llll}\text { Where, } & \mathrm{P}_{\mathrm{m}} & \text { Momentum buoyancy term } & (\mathrm{kg} / \mathrm{m} . \mathrm{s}) \\ \mathrm{g} & \text { Acceleration due to gravity } & \left(\mathrm{m} / \mathrm{s}^{2}\right) \\ \beta & \text { Thermal expansion coeffiecient } & (1 / \mathrm{K}) \\ \mathrm{T} & \text { The local real temperature } & (\mathrm{K}) \\ \mathrm{T}_{\mathrm{ref}} & \text { The reference real temperature } & (\mathrm{K})\end{array}$


The potential temperature, $\theta$, can be related to the real temperature, $\mathrm{T}$ using a form of the ideal gas law. The relevant term to be included in the transport equations for Turbulent Kinetic Energy is:

$$
\mathrm{P}_{\mathrm{k}}=-\frac{\mu_{\mathrm{eff}}}{\sigma_{\mathrm{H}}} \beta \mathrm{g} \frac{\partial \mathrm{T}}{\partial \mathrm{z}}
$$

Where,

$$
\begin{array}{ll}
P_{k} & \text { Buoyancy term for } k \\
\mu_{\text {eff }} & \text { Effective fluid viscosity } \\
\sigma_{\mathrm{H}} & \text { Turbulent Prandt number for heat }
\end{array}
$$$$
\left(\mathrm{m}^{2} / \mathrm{s}^{2}\right)
$$

The additional term to include the effect of buoyancy forces on the rate of dissipation of Turbulent Kinetic Energy is:

$$
\mathrm{P}_{\varepsilon}=\mathrm{C}_{1 \varepsilon} \frac{\varepsilon}{\mathrm{k}} \mathrm{P}_{\mathrm{k}}
$$

Where,

$$
\begin{array}{ll}
\mathrm{P}_{\varepsilon} & \text { Buoyancy term for } \varepsilon \\
\mathrm{C}_{1 \varepsilon} & \text { Modelling constant }
\end{array}
$$

\begin{tabular}{|c|c|c|c|}
\hline \multirow{3}{*}{ Where, } & $\mathrm{H}$ & Total fluid enthalpy & $(\mathrm{J} / \mathrm{kg})$ \\
\hline & $\lambda$ & Thermal conductivity of the fluid & $(\mathrm{W} / \mathrm{m} . \mathrm{K})$ \\
\hline & $\mu_{\mathrm{T}}$ & Turbulent viscosity & (kg/m.s) \\
\hline
\end{tabular}

In addition to the standard conservation equations used in RANS simulations it is also necessary to model the movement of thermal energy throughout the domain. This is achieved by ensuring that Eq. 19 is satisfied for all control volumes:

$$
\frac{\partial}{\partial t}(\rho H)+\frac{\partial}{\partial x_{j}}\left(\rho U_{j} H\right)=\frac{\partial}{\partial x_{j}}\left[\left(\frac{\lambda}{C_{p}}+\frac{\mu_{T}}{\sigma_{H}}\right) \frac{\partial H}{\partial x_{j}}\right]
$$

\section{Results}

\subsection{Quality metric}

The Pearson Correlation Coefficient, $\mathrm{R}$, metric gives an appreciation of the linearity of the relationship between two sets of data. It is one of the most commonly used and widely understood quality metrics. In Eq. 19, E represents experimental values, from the wind tunnel, and $\mathrm{S}$ represents simulated values. An over bar denotes the mean of a given dataset and $\sigma$ the standard deviation.

$$
R=\frac{(\overline{(E-\bar{E})(S-\bar{S}})}{\sigma_{E} \sigma_{s}}
$$

The optimum value for this metric is $R=1$. 
The results for the simulation of velocity and Turbulent Kinetic Energy in the wake of the model forest for the neutral and stable simulations are provided in the following Sections: 
4.2. Velocity

\subsubsection{Velocity Profiles}

In order to provide a direct comparison between the neutral and stable datasets, velocities have been normalised to the free stream values for each of the ten profiles in the wake of the forest. These are $2.5 \mathrm{~m} / \mathrm{s}$ and $1.5 \mathrm{~m} / \mathrm{s}$ for the neutral and stable data respectively. In each graph the normalised velocity is displayed on the horizontal whilst the height in metres is given on the vertical. The Pearson Correlation Coefficient, $\mathrm{R}$, is included for each profile.

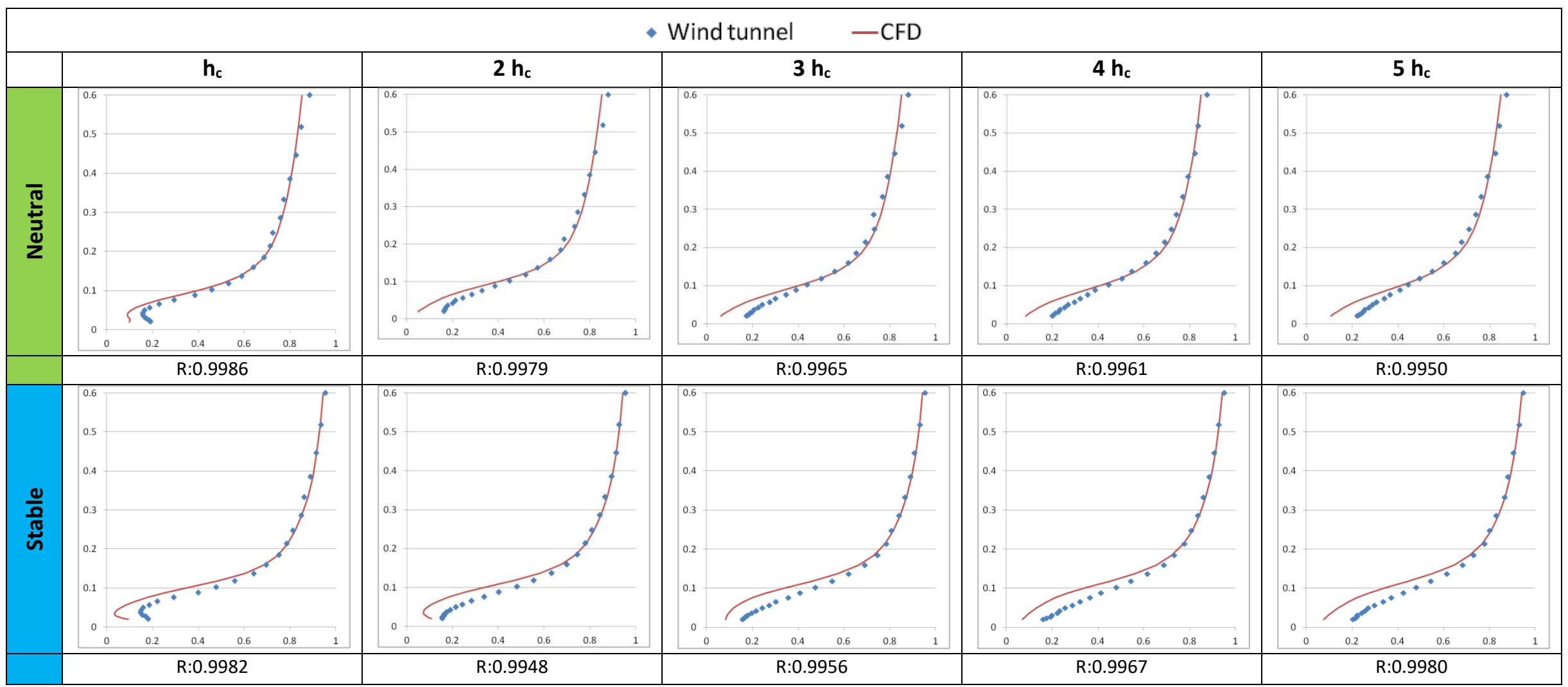

Figure 8. Comparison of CFD and wind tunnel velocity profiles for the neutral and stable stratifications for $h_{c}$ to $5 h_{c}$. Details of axes labels are given in the preceding text. 


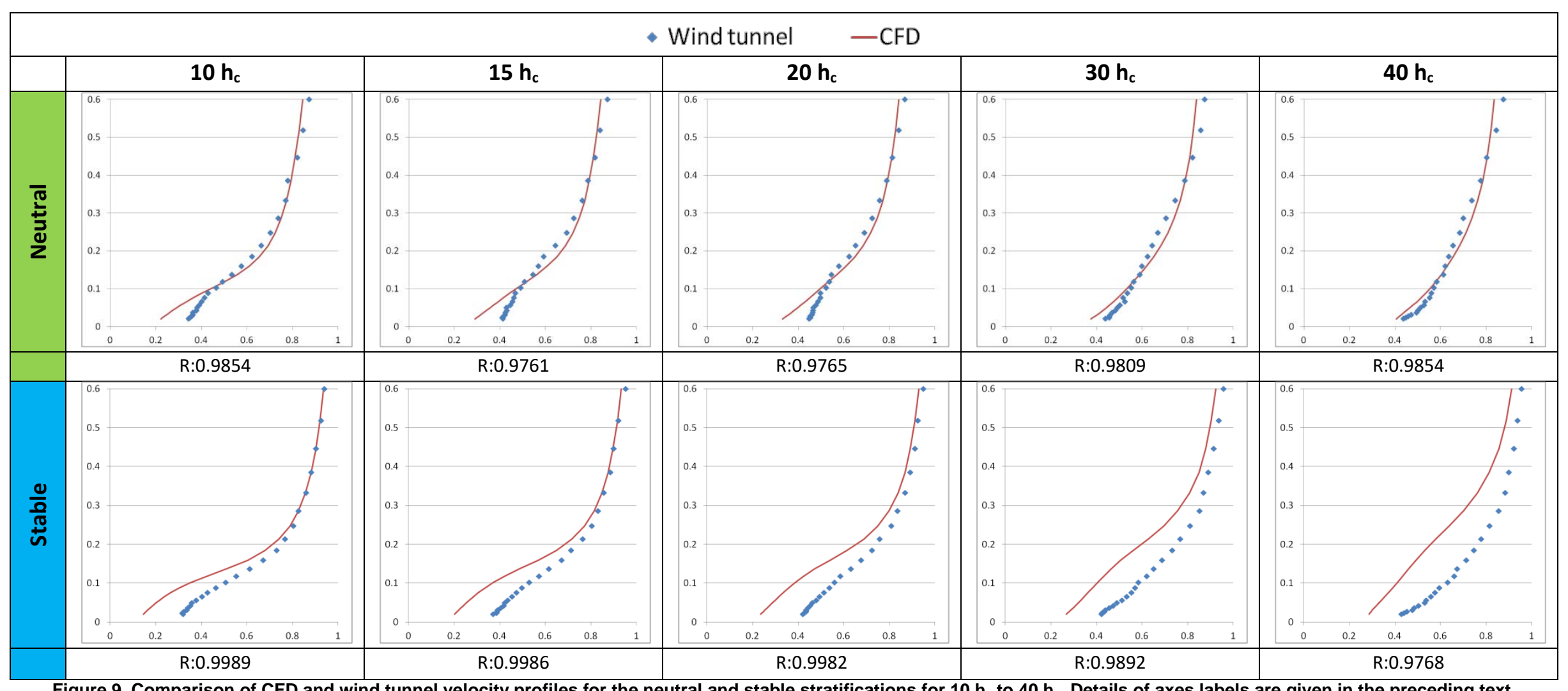

Figure 9. Comparison of CFD and wind tunnel velocity profiles for the neutral and stable stratifications for $10 h_{c}$ to $40 h_{c}$. Details of axes labels are given in the preceding text. 


\subsubsection{Line 1 \& Line 2}

Velocity values for Line 1 and Line 2, as detailed in Figure 3, are provided in Figure 10. Velocity values have been normalised to the free stream values, i.e. $2.5 \mathrm{~m} / \mathrm{s}$ and $1.5 \mathrm{~m} / \mathrm{s}$ for the neutral and stable data respectively.

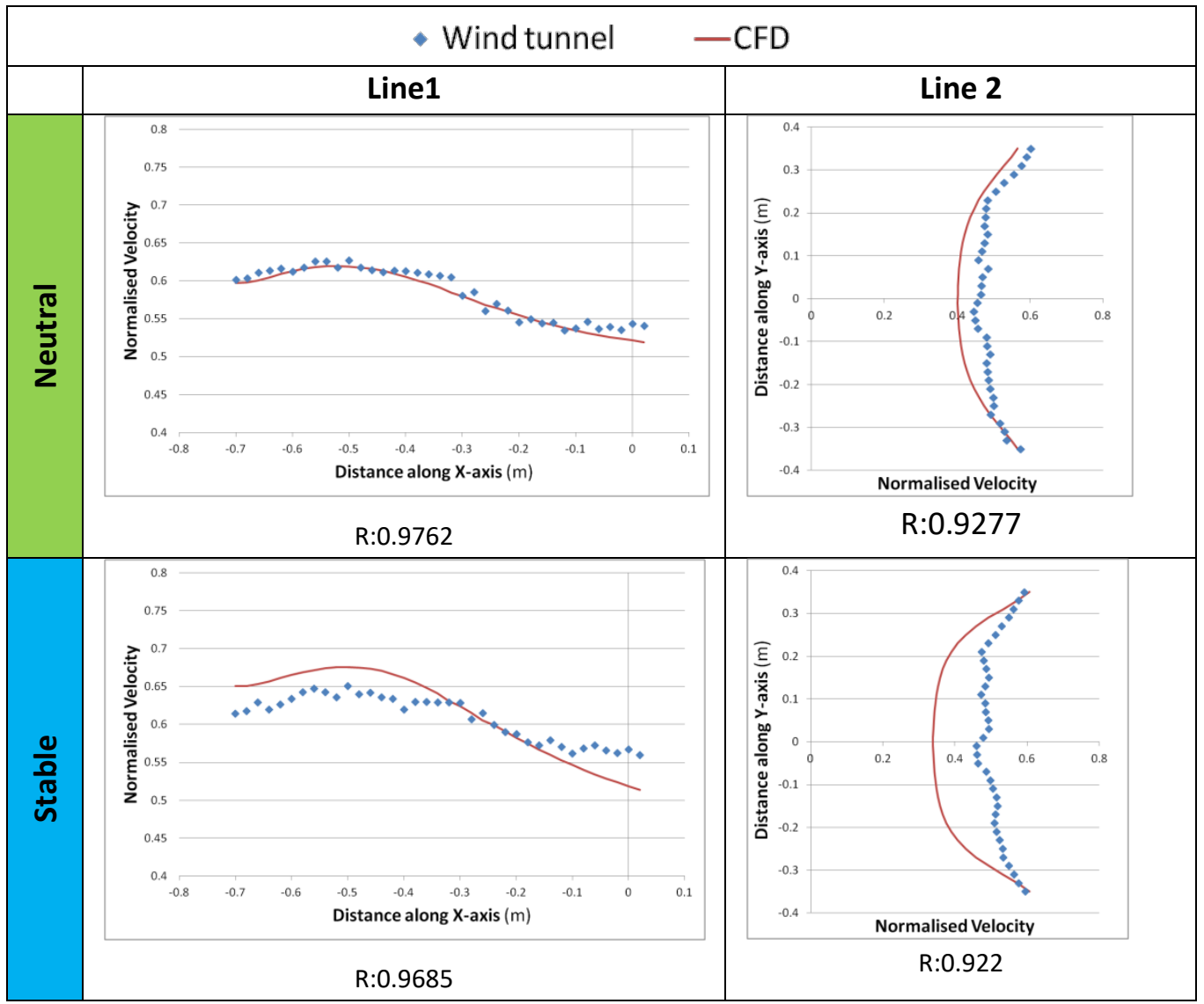

Figure 10. Comparison of CFD and wind tunnel velocity values for the neutral and stable stratifications for Line 1 and Line 


\subsection{Turbulence}

\subsubsection{Turbulence Profiles}

In order to provide a direct comparison between the neutral and stable datasets, Turbulent Kinetic Energy values have been normalised to the square of the free stream velocity values for each of the ten profiles in the wake of the forest. In each graph the normalised Turbulent Kinetic Energy is displayed on the $x$-axis whilst the height in metres is given on the $y$-axis.

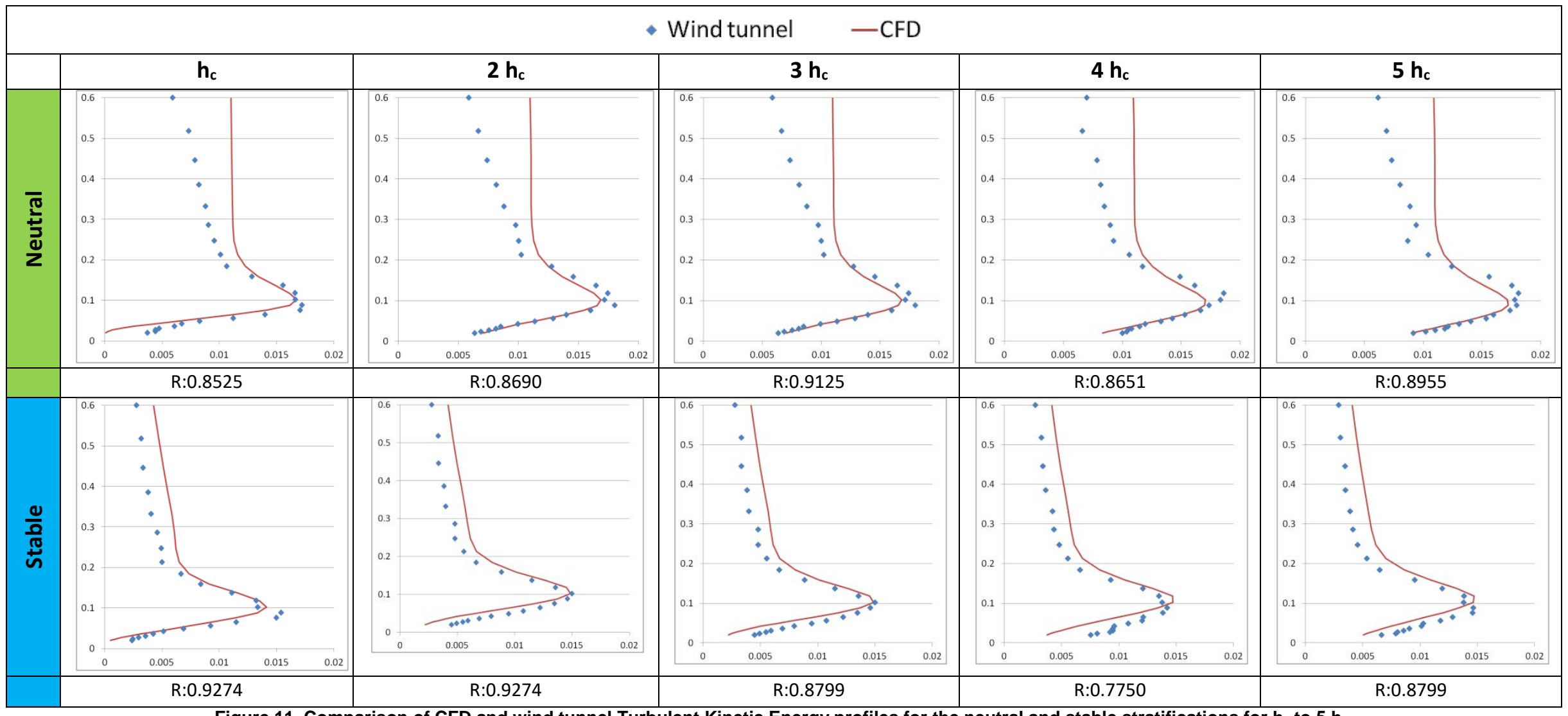

Figure 11. Comparison of CFD and wind tunnel Turbulent Kinetic Energy profiles for the neutral and stable stratifications for $h_{c}$ to $5 h_{c}$.

Details of axes labels are given in the preceding text. 


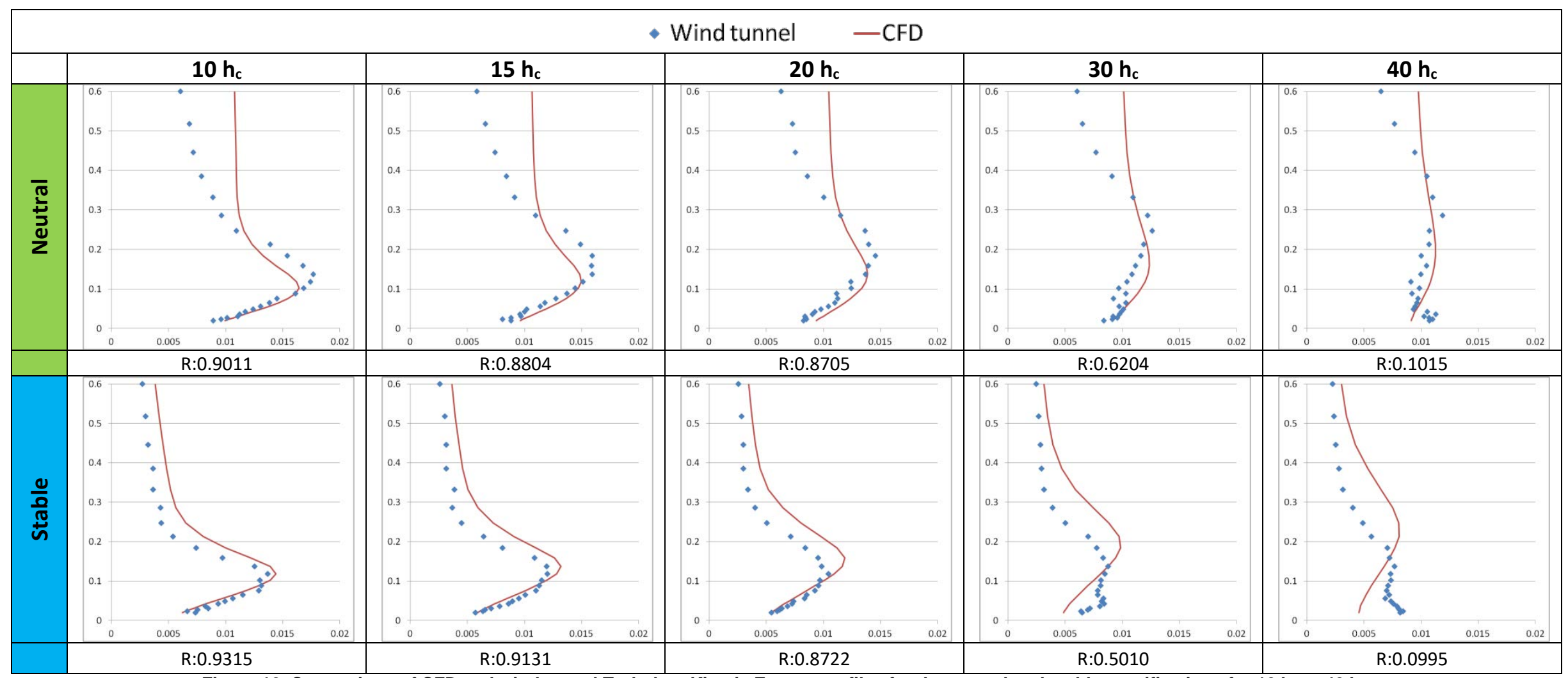

Figure 12. Comparison of CFD and wind tunnel Turbulent Kinetic Energy profiles for the neutral and stable stratifications for $10 h_{c}$ to $40 h_{c}$ Details of axes labels are given in the preceding text. 


\subsubsection{Line 1 \& Line 2}

Turbulent Kinetic Energy values are given for Line 1 and Line 2, as detailed in Figure 3, are provided in Figure 13. Turbulent Kinetic Energy values have been normalised to the square of the free stream velocity values. These are $2.5 \mathrm{~m} / \mathrm{s}$ and $1.5 \mathrm{~m} / \mathrm{s}$ for the neutral and stable data respectively.

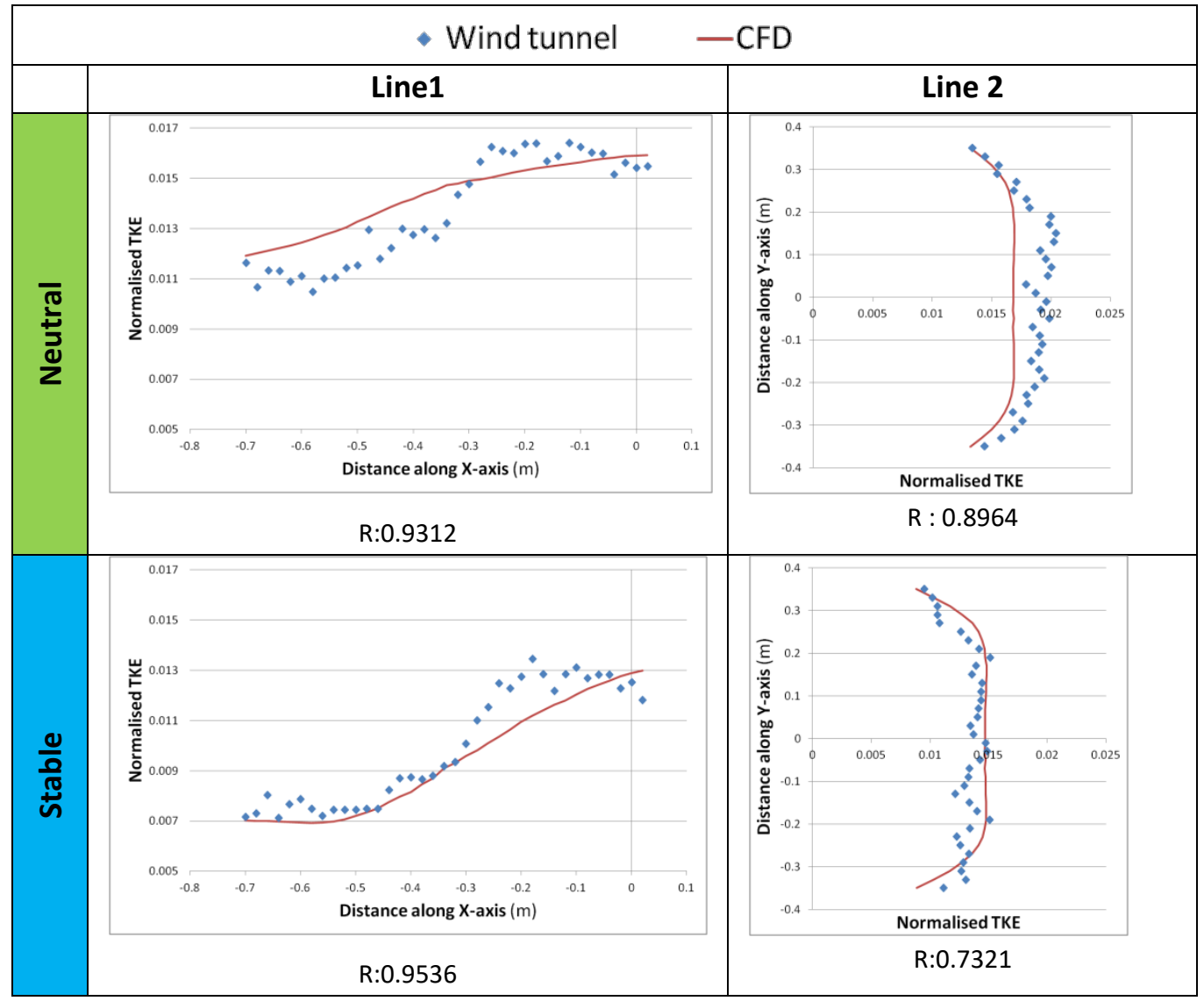

Figure 13. Comparison of CFD and wind tunnel Turbulent Kinetic Energy values for the neutral and stable stratifications for Line 1 and Line 2 


\section{Discussion}

\subsection{Velocity}

\subsubsection{Wind tunnel experiments}

The effects of stability are very much in evidence in the wind tunnel velocity data shown in Figure 8 and Figure 9 . The boundary layer is characterised by an increased wind shear which is well described by the stable form of the log law as outlined in Section 3.2. The flow within the tunnel was thermally stratified at the inlet and by cooling the floor from $7 \mathrm{~m}$ onwards before being characterised using LDA upstream of the forest. The resultant thermal stratification has very clearly had an impact on the wind characteristics, which are in line with atmospheric theory, and so the experiments can be viewed as a success from that point of view.

Examining the wind tunnel velocity data at $30 \mathrm{~h}_{\mathrm{c}}$ in Figure 9 we see that in the neutral experiment the flow has returned to an approximately logarithmic profile. However, in the stable wind tunnel dataset also shown in Figure 9, the effect of the forestry is still apparent with a slight inflection at a height approximately equal to the mean canopy height. This again shows that the experimental velocity data is in line with the expectation that wake effects will persist for greater distances in the lee of the obstruction which caused them under stable stratification.

Examining the wind tunnel velocity data at $h_{c}$, we see further evidence of the effects of stability with the magnitude of the sub-canopy jet being slightly more pronounced in the stable data, Figure 8 . Field measurement campaigns of canopy flows have suggested that this canopy flow feature is more prevalent under stable atmospheric stratifications (Su et al., 2008). Also, as the sub-canopy jet is a wake feature, we would expect that it would persist for a greater distance downstream in an environment where vertical fluxes are inhibited. This assumption is borne out in examination of the experimental data.

In both the neutral and stable datasets there is a slight initial velocity increase followed by a more significant decrease at 400-500 $\mathrm{mm}$. These measurements are in line with expectations following calculation of a canopy adjustment length of $479 \mathrm{~mm}$ in Desmond et al. (2014).

\subsubsection{CFD simulations}

The effects of the imposed stability are also very much apparent in the CFD velocity data in Figure 8 and Figure 9. The recovery of the logarithmic profile is considerably slower in the stable simulation with the effect of the canopy still very much apparent at $40 \mathrm{~h}_{\mathrm{c}}$ in Figure 9. In addition, the subcanopy jet is still visible at $2 \mathrm{~h}_{\mathrm{c}}$ for the stable simulation whilst it has been eradicated at this stage in the neutral data. There is also a considerably more pronounced increase and subsequent decrease in the velocity measurements for Line 1 in the stable simulation, Figure 10. As discussed in Section 5.1.1 this may be an effect attributable to thermal stability.

In terms of validation quality, there is very good agreement between the neutral CFD simulation and the corresponding wind tunnel experiment in respect of velocity data for all considered profiles in the wake of the model forest. The agreement is particularly strong above $0.1 \mathrm{~m}$, the approximate canopy height, as can be seen in Figure 8 and Figure 9. Also, both the numerical and physical model show recovery of the wind speed to a logarithmic profile at between $20-30 h_{c}$. There is also very good agreement for Line 1 and Line 2 as shown in Figure 10. These findings confirm the analysis of 
neutral canopy flow simulations presented in Desmond et al. (2014) and provide a suitable bench mark for comparison with the stratified datasets.

Examining the quality of the stably stratified CFD simulation in Figure 8 and Figure 9, we see that there is generally good agreement in the characteristics of the velocity profiles. Both the physical and numerical models capture the detail of the sub canopy jet and show an inflection in the profiles at approximately $0.2 \mathrm{~m}$. However, there is considerable divergence below this height which becomes exaggerated beyond $15 h_{c}$ until the agreement for the entire profile degrades significantly by $40 h_{c}$ as shown in Figure 9.

Generally, it appears that the CFD is overestimating the effects of thermal stratification in terms of how long it takes the wind field to recover following the obstruction. This trend is highlighted by examination of the Pearson's Correlation Coefficients for subsequent profiles in Figure 8 and Figure 9 which are summarised in Figure 14.

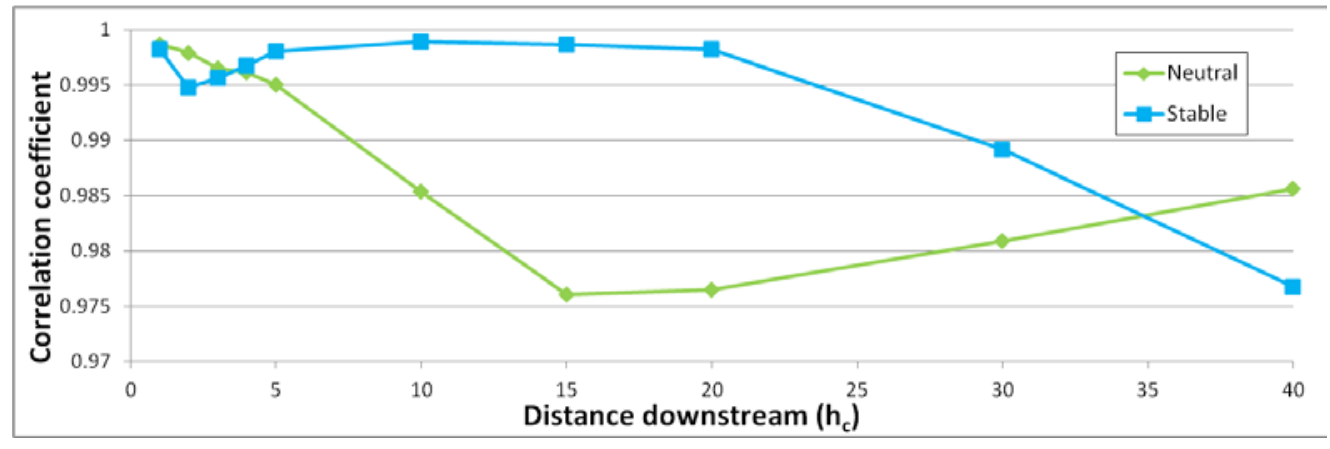

Figure 14. Parson's Correlation Coefficient values comparing CFD and wind tunnel velocity profiles at various distances downstream of the forest for the neutral and stable cases.

The high Correlation Coefficient values for the stable simulations shows that the overall characteristics of the velocity profile, though not necessarily the absolute values, are accurately modelled up until approximately $20 \mathrm{~h}_{\mathrm{c}}$ where there is a rapid decline in quality. On the other hand, the neutral simulations quality experiences a sudden drop at $10-20 \mathrm{~h}_{\mathrm{c}}$ but ultimately recovers as the flow returns to a logarithmic profile. A similar recovery is not experienced for the stable CFD simulation where the effects of stability cause a divergence from the observed velocity values.

This overestimation of the effects of stability is also clearly shown for data relating to Line 1 and Line 2 in Figure 10. In Line 1, we observe a much more rapid increase and subsequent decrease in the velocity for the stable CFD simulation. This feature may be attributable to the effects of stability due to a limited cascade of energy from the free stream creating a greater sensitivity of the flow to the underlying roughness, however, such a phenomenon is not observed in the corresponding experimental data. In the data for Line 2 we see an increased divergence from observed velocity values in the stable simulations directly in the lee of obstruction which may again suggest an overestimation of the effects of stability. 


\subsection{Turbulence}

\subsubsection{Wind tunnel experiments}

There is a stark contrast between the magnitude of the free stream normalised Turbulent Kinetic Energy values for the stable and neutral experiments in Figure 11 and Figure 12. As the placement and height of the roughness elements within the tunnel are identical for both configurations, the reduced $\mathrm{k}$ values in the stable experiment must be due to the inhibition of turbulent fluxes imposed by the stratification. This effect can also be observed at, for instance, $4 \mathrm{~h}_{\mathrm{c}}$ in Figure 11 where the peak for the normalised $\mathrm{k}$ values in the neutral experiment are approximately 0.02 as compared to 0.015 for the stable case.

Another interesting difference between the stable and neutral experimental data can be observed for profiles between 10 and $30 \mathrm{~h}_{\mathrm{c}}$ downstream in Figure 12. In the neutral data, the peak in $\mathrm{k}$ caused by the presence of the forest gradually moves from $0.1 \mathrm{~m}$ to $0.3 \mathrm{~m}$ much as was observed for the Orléans dataset in Desmond et al. (2014). However, in the stable experiments the peak in k remains at $100-150 \mathrm{~mm}$ for each of the profiles. Such an effect may be expected under stable stratification where buoyancy forces and reduced ambient Turbulent Kinetic Energy values would limit vertical propagation of wake effects.

Aside from these obvious differences, evidence for the existence of the wake persists in the $\mathrm{k}$ profiles for both the neutral and stable experiments up to $40 \mathrm{~h}_{\mathrm{c}}$. These values are in line with the extent of the turbulent wake simulated for the Orléans experiments in Desmond et al. (2014). In addition, examination of the values measured across Line 1, shown in Figure 13, again show a similar trend for both the stable and neutral experiments, with a steep ramp in measured values at approximately $450 \mathrm{~mm}$ from the canopy edge which then reaches an equilibrium for the remainder of the obstruction. Again these measurements are in line with expectations following calculation of a canopy adjustment length of $479 \mathrm{~mm}$ in Desmond et al. (2014).

\subsubsection{CFD simulations}

The inlet Turbulent Kinetic Energy profile in the neutral simulations does not decrease with height as was observed in the tunnel. This is due to the fact that we used the standard Richards and Hoxey equations to determine the profile in order to be consistent with the approach used for the Orléans simulations in Part II. This reduction in $\mathrm{k}$ with height is achieved in the stable CFD simulations using the stability dependant version of the Richards and Hoxey equations, as outlined in Section 5.2.1. Good agreement between the stable atmospheric theory and observations in the tunnel ensure that ambient turbulence levels are accurately reproduced.

Stability effects are again apparent in the CFD profiles presented in Figure 11 and Figure 12 with a reduced turbulence peak at $100 \mathrm{~mm}$ for the stable simulations. If we again examine values at $4 \mathrm{~h}_{\mathrm{c}}$ in Figure 11 we see that the peak normalised turbulence level in the neutral simulation is 0.017 compared to 0.015 in the stable. This effect is also observed in the wind tunnel data, however, the magnitude is greater.

In terms of validation quality, the overall trend in the magnitude of Turbulent Kinetic Energy is well captured for both the stable and neutral simulations, with a slight deviation for the stable data below $100 \mathrm{~mm}$, as shown in the series of graphs in Figure 11. In Figure 12, we see a significant disparity for the height of the peak $\mathrm{k}$ value in the neutral simulation with a gradual divergence from the observed height between 10 and $30 h_{c}$. A similar disparity is observed in the stable data set where the CFD predicts a gradual increase in the height of the peak $\mathrm{k}$ value between 10 and $30 \mathrm{~h}_{\mathrm{c}}$ 
which is not seen in the experimental data. Thus, it is clear that the effect of stability on the growth of the turbulent wake is not well captured in the stratified CFD simulation. Also, there is again evidence of the over estimation of the effects of the stable stratification in the CFD with the perturbation to the k profile still apparent at $40 \mathrm{~h}_{\mathrm{c}}$ in Figure 12.

These limitations aside, the agreement of the simulated and experimental values of Turbulent Kinetic Energy in the wake of the forest is good for both the neutral and stable profiles for up to 20 $\mathrm{h}_{\mathrm{c}}$ in the lee of the obstruction with a similar reduction in quality for both cases thereafter. This trend is evidenced by the Pearson Correlation Coefficient values for each profile which is presented in Figure 15.

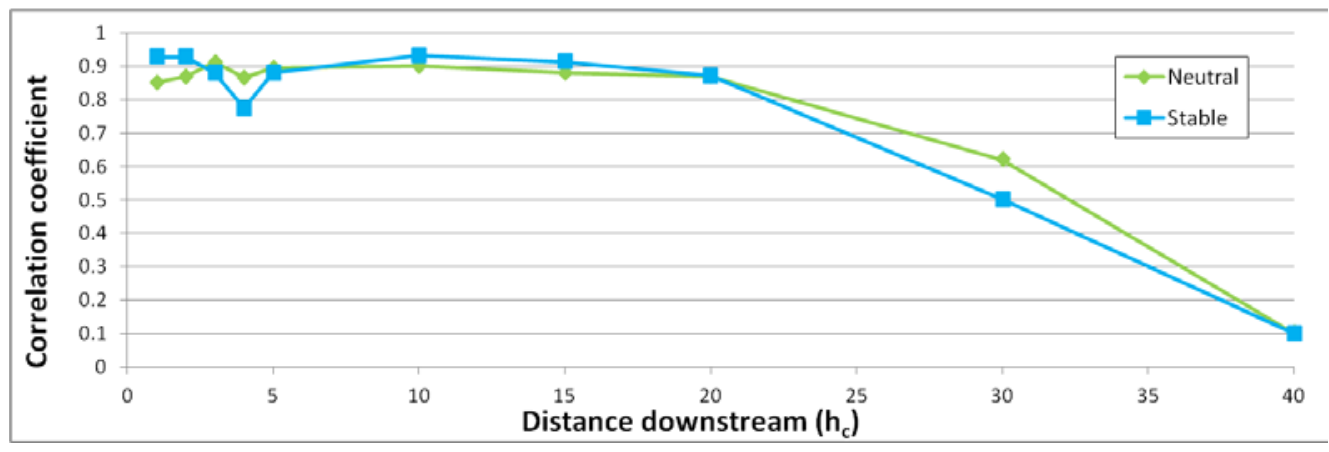

Figure 15. Parson's Correlation Coefficient values comparing CFD and wind tunnel TKE profiles at various distances downstream of the forest for the neutral and stable cases.

Examining the data for Line 1 and Line 2 in Figure 13 we see that the stable simulation significantly outperforms the neutral in respect of capturing the magnitude of the Turbulent Kinetic Energy. The results for Line 1 show that the stable simulation is more successful in capturing the rapid increase in values at approximately $450 \mathrm{~mm}$ from the canopy edge. Similarly, the results for Line 2 show a much greater correlation with observations. It is quite likely that this is simply a result of the better match in the $\mathrm{k}$ inlet profile achieved using the stable form from of the atmospheric theory equations.

\section{Conclusions}

There is significant variation in the level of agreement between the CFD validation simulations and the experimental data for the neutral and stable canopy flows, presented in Section 4. However, both the CFD and the experimental data show very definitely that atmospheric stability, in this case stable stratification, has a significant effect on the wind characteristics and also the development and extent of the forest wake. As the analysis in Desmond and Watson (2014) showed that such atmospheric conditions are common in forested areas, it is thus important to consider these effects in our resource assessments.

What is less clear from the analysis is whether changes to the extent and shape of the wake in the stable CFD simulation are simply due to the altered wind speed and turbulence profiles prescribed at the boundaries or if they are due to the additional buoyancy physics included in the calculations. In order to investigate this point, an additional simulation was conducted using the stable boundary conditions outlined in Section 3.2 but removing the surface heat flux and the thermal stratification within the domain. Otherwise, the boundary conditions for velocity and turbulence and the model configuration remained as described in Section 3.2. the An abridged version of the results is shown in Figure 16. 


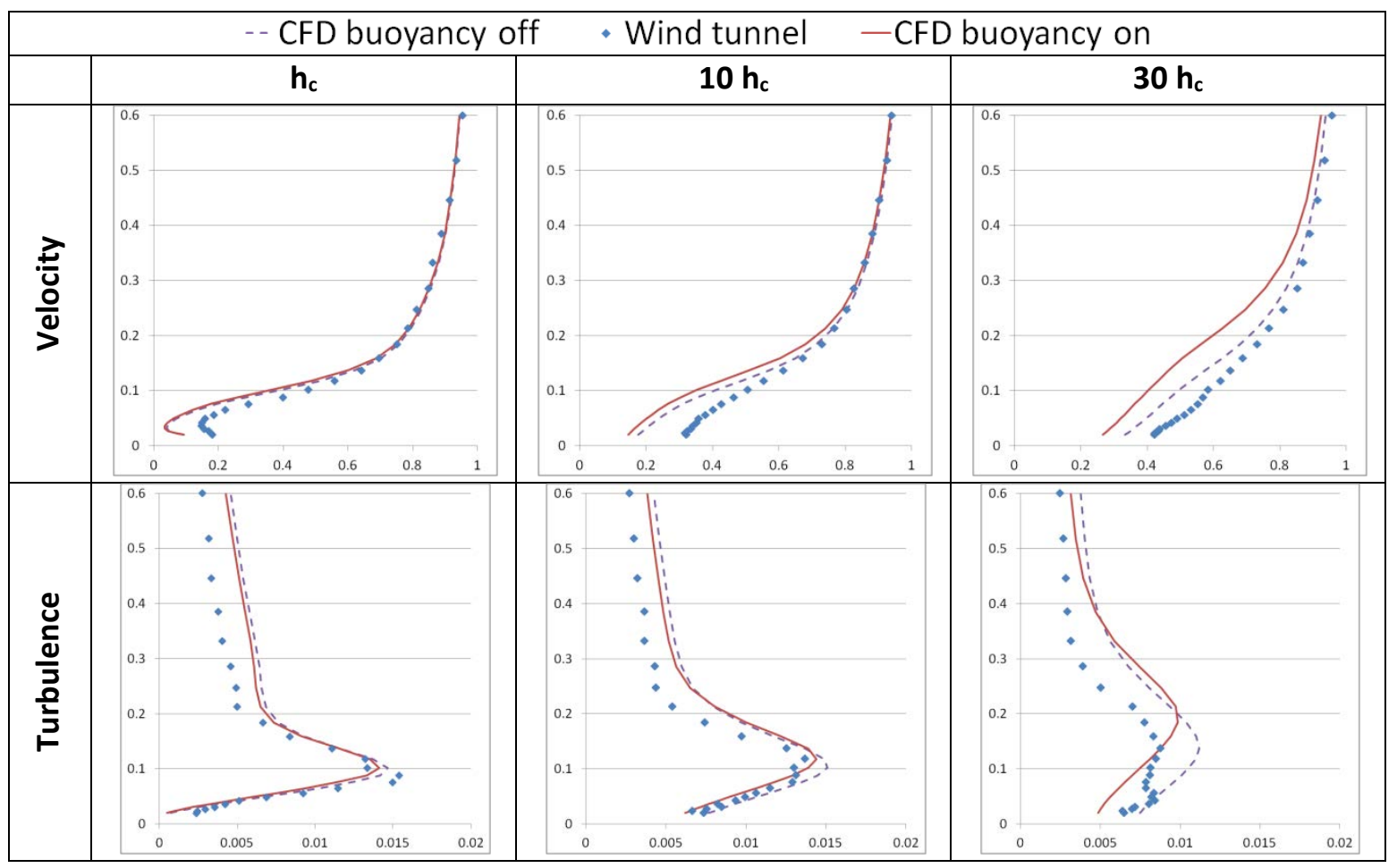

Figure 16. Abridged CFD results using the stable boundary conditions outlined in Section 3.2 with thermal stratification and surface heat flux included and excluded. In each graph the height in metres is shown on the vertical axis whilst the normalised velocity or normalised TKE are shown on the horizontal.

As can be seen in Figure 16, the CFD simulation in which buoyancy effects are not included matches the CFD simulation in which these additional physics are included very well for both normalised velocity and turbulence profiles at $h_{c}$. However, as we move downstream of the obstruction the buoyancy forces come into play and the simulation in which they are included shows a slower recovery of the velocity a logarithmic profile along with reduced normalised Turbulent Kinetic Energy values. This would indicate the CFD is replicating the effects of stability in the simulation in which stratification and surface heat flux are included, however, the magnitude of these effects is clearly overestimated.

It may be possible to reduce this overestimation by altering the thermal stratification within the CFD domain, or tuning the various modelling constants, to identify a configuration in which the velocity and turbulence levels simulated are in agreement with the wind tunnel data. However, this would be a time consuming and ultimately pointless exercise as the findings will only be relevant to this very particular flow situation.

Another possible source of error in the numerical study could be the assumed relationships for mean and turbulent components of the velocity presented in Eq. 1 and Eq. 2. This relationship could be assessed using additional instrumentation in the EnFLo facility and/or conducting a sensitivity analysis to the prescribed relationship in the CFD.

Also, in this study a smooth no-slip condition has been applied to the floor boundary in the CFD rather than prescribing a rough surface with elements of height equal to the equivalent sand-grain roughness calculated using Eq. 4 . This approach is analogous to conditions in the tunnel, where 
roughness elements were not present behind the model forest, and allowed the use of a fine mesh. However, the prescribed boundary conditions may have had consequences on the heterogeneity of the $A B L$ in the CFD simulation. A discussion on this important aspect of CFD simulation can be found in Blocken et al. (2007) and more recently Juretić et al. (2013).

The presented analysis has shown that stable stratifications have a significant impact on the characteristic of canopy flows and that it is possible to include both forestry and buoyancy effects in CFD simulations using the CFX software without incurring mathematical difficulties. Future work will examine real world data from a forested site and extend the analysis to include unstable stratifications.

\section{Acknowledgments}

This work has been carried out with funding from the EU FP7-PEOPLE program under WAUDIT Marie-Curie Initial Training Network and EPSRC SUPERGEN-Wind EP/D034566/1.

\section{References}

ANSYS, 2017. CFX-Solver Theory Guide, Release 18.0, January 2017.

Blocken B., Stathopoulos T., Carmeliet J., 2007. CFD simulation of the atmospheric boundary layer: wall function problems. Atmospheric Environment, Vol. 41, No. 2, pp. 238-252.

Brower M.C., 2012. Findings of investigations into underperforming sites. Proceedings of EWEA Technology Workshop, Lyons, France, 2-3 July, 2012.

Brunet, Y., Irvine, R., 2000. The control of coherent eddies in vegetation canopies: Streamwise structures spacing, canopy shear scale and atmospheric stability. Boundary Layer Meteorology, Vol. 94., pp 139-163.

Desmond, C., Watson S., 2014. A study of stability effects in forested terrain. Journal of Physics: Conference Series 555.

Desmond C., Watson S., Aubrun S., Avila S., Hancock P., Sayer A., 2014 a. A study on the inclusion of forest canopy morphology data in numerical simulations for the purpose of wind resource assessment. Journal of Wind Engineering and Industrial Aerodynamics, Vol. 126, pp. 24-37.

Hancock, P.E., Zhang, S., Hayden, P., 2013. A wind tunnel artificially thickened simulated weakly unstable atmospheric boundary layer. Boundary Layer Meteorology, Vol. 149, pp. 355-380.

Juretić, F., Kozmar, H., 2013. Computational modeling of the neutrally stratified atmospheric boundary layer flow using the standard $k-\varepsilon$ turbulence model. Journal of Wind Engineering and Industrial Aerodynamics 115, pp. 112-120.

Kaimal, J.C., Finnigan, J.J., Atmospheric boundary layer flows. Oxford University Press, 1994.

Lopes da Costa J.C.P., Atmospheric flow over forested and non forested complex terrain. PhD thesis, University of Porto, 2007.

Mannan S and Lee F 2005 Lee's Loss Prevention in the Process Industries (London: Elsevier) 
McCormick, S., Montavon, C., Jones, I., Staples, C., Sinai, Y., Atmospheric boundary layer - Boundary layer conditions and profiles. WindModeller Manuals. ANSYS, 2012.

Menter, F.R., 1994. Two equation eddy viscosity turbulence models for engineering applications. AIAA Journal 32, No. 8, pp. 1598-1605.

Meroney, R.N., Ten questions concerning hybrid computational/physical model simulation of wind flow in the built environment. Building and Environment, Vol 96, pp. $12-21$.

Meroney, R.N.,Neff, D.E., Wind tunnel modelling of hill and vegetation influences on wind power availability. Proceedings of Wind Energy and Landscape (WEL), Satellite International Workshop of the 2nd European \& African Conference on Wind Engineering (2 EACWE), Genova, Italy, June 26-27, $1997,10 \mathrm{pp}$

Montavon C., Simulation of atmospheric flows over complex terrain for wind power potential assessment. PhD thesis, École Polytechnique Fédérale de Lausanne, 1998.

Morse, A.P., Gardiner, B.A., Marshall, B.J., 2001. Mechanisms controlling turbulence development across a forest edge. Boundary Layer Meterology, Vol. 130, pp. 227-251.

Mortensen N., Jørgensen H., 2013. Comparative Resource and Energy Yield Assessment Procedures. Proceedings of European Wind Energy Association Technology Workshop: Resource Assessment, Dublin, June 2013.

Richards P.J., Hoxey R.P., 1993. Appropriate boundary conditions for computational wind engineering models using the k-e turbulence model. Journal of Wind Engineering and Industrial Aerodynamics, Vol. 46, pp. 145-153.

Sanz Rodrigo J., State of the art of Wind Resource Assessment: Deliverable D7 of the Waudit project. CENER, Spain, 2010.

Schröder, A., Willert, C.E., Particle image velocimetry. New developments and recent applications. Springer, 2008.

Sogachev, A., 2009. A note on two equation closure modelling of canopy flow. Boundary Layer Meteorology 130, pp. 423-435.

Sogachev, A., Kelly, M., Leclerc, M.Y., 2012. Consistent two equation modelling for atmospheric research. Buoyancy and vegetation implementations. Boundary Layer Meteorology 145. No. 2, pp. 307-327.

Su, H.B., Schmid H.P., Vogel C.S., Curtis P.S., 2008. Effects of canopy morphology and thermal stability on mean flow and turbulence statistics observed inside a mixed hardwood forest, Agricultural and forest meteorology, Vol. 148, pp. 862-882.

Thacker, A., Loyer, S., Aubrun, S. Comparison of turbulence length scales assessed with three measurement systems in increasingly complex turbulent flows. Experimental Thermal and Fluid Science, Vol. 34, Issue. 5., 2010. 
TPWind, 2008. Strategic research development agenda. Market development strategy from 2008 to 2030. The European Wind Energy Technology Platform, Brussels.

Troen I., De Bass A., 1986. A spectral diagnostic model for wind flow simulations in complex terrain. Proceedings of European Wind Energy Conference, Rome, 1986.

Wylie, S.J., CFD modelling of wind flow through and around forest canopies, PhD. thesis, Loughborough University, 2014.

Zhang, M., Shen, G., Wei, R., Error analysis of stereoscopic particle image velocimetry. In: Proceedings of SPIE 5058, Optical Technology and Image Processing for Fluids and Solids Diagnostics, 2002.

Zilitinkevich S., Johansson P.E., Mironov D.V., Baklanov A., 1998. A similarity-theory model for wind profile and resistance law in stably stratified planetary boundary layers. Journal of Wind Engineering and Industrial Aerodynamics, Vol. 74-76, pp. 209-218. 